\title{
THE SHIELDING DESIGN OF BESSY II*
}

\author{
K. Ott ${ }^{\dagger}$, BESSY, Rudower Chaussee 5, 12489 Berlin, Germany
}

\begin{abstract}
BESSY II consists of a $50 \mathrm{MeV}$ microtron, a maximum energy synchrotron and the $1.9 \mathrm{GeV}$ storage ring. The investigations of the radiation types occuring at those machines dependent of the electron energy, target and shielding materials, observating angles and geometric aspects are well established, often condensed in semi-empiric formulas and in good agreement with the results of the Monte Carlo programs EGS4 and FLUKA. But as important as the pure physical aspects of radiation are for a shielding design the operating times and modes and the consideration of possible crash scenarios. We present here a new approach of considering failure operating probabilities at electron storage rings based on years of radiation and operating observations of BESSY I. The shielding design of BESSY II was developed using a C++ class library which includes the most recent models for all radiation types and the new failure operating probability approach. Calculations and first measurement results of the commissioning are presented too.
\end{abstract}

\section{LAW AND BUILDING UTILIZATION}

For a shielding design of an electron storage ring facility are as relevant as the physical parameters the conditions given by law, operating times and planned utilization of machine and building. In Germany the annual personal doses of radiation workers (category B) and non-radiation workers are limited to $15 \mathrm{mSv} / \mathrm{a}$ and $5 \mathrm{mSv} / \mathrm{a}$ respectively.

If local doses can be higher than $15 \mathrm{mSv} / \mathrm{a}$ (2000 h stay) the respective area is a so called control area in which only radiation workers with personal dosimeters have access.

If at any failure operating (e.g. closed valve in the storage ring and full injection rate) the dose rate in an area could be higher than $3 \mathrm{mSv} / \mathrm{h}$ this area is a so called restricted area. Such an area has to be secured with a personal safety system, so that entering of it result in an immediate stop of radiation production.

The area accessible for the generality is named general area and has an annual dose limit of $0.3 \mathrm{mSv} / \mathrm{a}$.

We decided, to hold this limit at the outer edge of the experimental hall, which would result in having no more than $2 \mathrm{mSv} / \mathrm{a}$ within the experimental hall.

The next design criterium was that the service area and the roof of both storage ring and synchrotron should be used for technical installations and so should be as accessible as the experimental hall with similar doses.

\footnotetext{
* funded by the Bundesministerium für Bildung, Wissenschaft, Forschung und Technologie and by the Land Berlin

† Email: ott@bessy.de
}

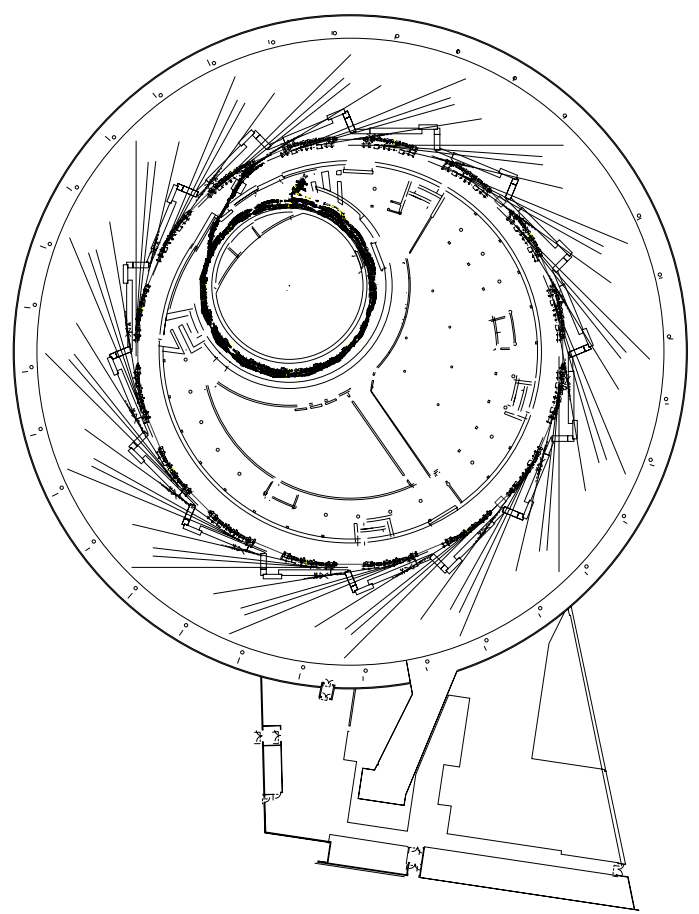

Figure 1: BESSY II overview

A further condition was that synchrotron and storage ring could be used independently to allow storage ring construction during synchrotron commissioning and later easy access for attendance work.

\section{OPERATING OF BESSY II}

For shielding design purposes, one has to distinguish between two cases of storage ring (synchrotron) operation:

a) The machine is used just to inject and produce synchrotron radiation (user mode).

b) The machine is used for machine tests, machine experiments and some phases of the commissioning (machine test mode).

The two modes differ considerable in electron losses and crash probabilities. 
Table 1: Operating times user mode

Operating of the storage ring / day

Operating of the storage ring / year

$\begin{array}{rl}24 & \mathrm{~h} \\ 6000 & \mathrm{~h} \\ 5 & \\ 1200 & \\ 15 & \mathrm{~min} \\ 300 & \mathrm{~h}\end{array}$

Injections / day

Injections / year

Operating of the synchrotron / injection

Operating of the synchrotron / year

Synchrotron radiation is absorbed in the vacuum system at BESSY II with the exception of wave length shifter beamlines with critical energies about $10 \mathrm{keV}$.

Gasbremsstrahlung at BESSY II can be about $300 \mathrm{mSv} / \mathrm{h}$ for normal pressure [4] and requires $25 \mathrm{~cm}$ lead for absorption.

\section{ELECTRON LOSSES}

We will give here an overview over the electron losses at BESSY II. The electron losses are for the most part results of the machine components and there possibilities of operating and therefore close to an optimized state of the machine.

$\begin{array}{lrl}\text { Weeks for machine tests / year } & 12 & \\ \text { Injections / day } & 10 & \\ \text { Injections / year } & 600 & \\ \text { Operating of the synchrotron / injection } & 15 & \mathrm{~min} \\ \text { Operating of the synchrotron / year } & 150 & \mathrm{~h}\end{array}$

\section{PHYSICAL ASPECTS}

The main contribution of the radiation doses at electron storage rings causes from the electron losses during the short injection periods. When electrons hit under small angles the vacuum system bremsstrahlung is produced. This bremsstrahlung causes electron positron pair production and therefore an electron photon cascade with a maximum energy at about $1 \mathrm{MeV}$ [3]. The bremsstrahlung also causes with $(\gamma, \mathrm{n})$ processes giant resonance neutrons and fast neutrons with quasi deuteron fission [8]. The energy spectrum of the giant resonance neutrons is mainly determined by the material of the target (vacuum system) and the in case of steel it is similar to the Cf spectrum with a maximum at $1 \mathrm{MeV}$ [7]. The production of myons in electro-magnetic cascades at electron accelerators is relevant for radiation safety from several GeV electron energy on. Because of an energy of $1.9 \mathrm{GeV}$ at BESSY II the radiation caused by myons is two to three orders of magnitude smaller [2] than the doses caused by neutrons and gamma radiation outside the shielding walls, so it is neglectable for this case.

The activity of the primary cooling circuit water (without ${ }^{15} \mathrm{O} \tau 2 \mathrm{~min}$ ) at DESY synchrotron is about $0.37 \mathrm{~Bq} / 1$ [6]. Radioactive substances are not given to the environment with water at BESSY II because of holding the cooling water of all machine components in closed cooling circuits.

The activation of accelerator components is at electron accelerators three orders of magnitude lower than at proton accelerators, because the activation is made here by secondary and ternary radiation. Another important point is, that at electron storage rings and synchrotrons the electron acceleration operates in pulsed mode therefore reducing the radiation power to a few watts. So altogether the activation of components of electron storage rings is typical 6 orders of magnitude lower than at proton or heavy ion accelerators.

Copper can cause some activation problems $(20 \mu \mathrm{Sv} / \mathrm{h}$ in $0.5 \mathrm{~m}$ distance) if exposed direct to the electron beam.

$\begin{array}{lll}\text { Microtron intern } & 70 \% & 15 \mathrm{MeV} \\ \text { Microtron extracted beam } & \text { crash } & \text { only } \\ \text { Transferline microtron-synchr. } & 5 \% & 50 \mathrm{MeV} \\ \text { Injection losses synchr. (a) } & 70 \% & 50 \mathrm{MeV} \\ & \text { puls } & 1 \mu \mathrm{s}->300 \mathrm{~ns} \\ & \text { single } & \text { turn injection } \\ \text { Injection losses synchr. (b) } & 50 \% & 50 \mathrm{MeV} \\ & \mathrm{RF} 3 \mathrm{GHz} & ->500 \mathrm{MHz}\end{array}$

Injection losses synchrotron (relation 4:3:3) to

$\begin{array}{ll}\text { Injection septum } & 40 \% \\ \text { Extraction septum } & 30 \% \\ \text { 10 Point sources }(10 \mathrm{~m}) & 30 \%\end{array}$

Extraction losses synchrotron

(a) $16 \% \quad 1.9 \mathrm{GeV}$ kicker puls $50 \mathrm{~ns} / 300 \mathrm{~ns}$

(b) $25 \% \quad 1.9 \mathrm{GeV} \quad$ Septum channel

Without extraction recirculation to $10-20 \mathrm{MeV}$

Losses to components (relation 4:3:3)

\begin{tabular}{lll}
\multicolumn{2}{c}{ Injection losses storage ring } \\
Transferline SY2ST & $10 \%$ & $1.9 \mathrm{GeV}$ \\
Injection septum channel & $30 \%$ & $1.9 \mathrm{GeV}$ \\
24 Point sources (10 m) & $40 \%$ & $1.9 \mathrm{GeV}$
\end{tabular}

Min. injection time: $32.9 \mathrm{sec}$ for $9.98 \cdot 10^{11} \mathrm{e}-(200 \mathrm{~mA})$

\section{FAILURE HANDLING}

The above result of 30 second injection time to fill the storage ring has to be considered as an optimized state.

The worst cases are total electron losses at one place with full injection rate. The newer models are optimized for typical target geometries and observation angles at accelerators. So the dose rates can be predicted with good accuracy. But the approaches to estimate an annual dose from the possible failure operating scenarios differ widely.

One approach is the opinion, that those failure scenarios seldom occur and so there contribution to the annual dose is neglectable [5]. Another approach is that at every machine component, as specified in the last section, $5 \%$ or 
$10 \%$ of the annual operating time such a worst case scenario occurs [6]. For the storage ring BESSY II the first approach would result in a $0.5 \mathrm{~m}$, for the second in a 1.5 $\mathrm{m}$ thick shielding wall. Both approaches are not easy to defend. The first because of obvious reasons, the second because of the fact, that the machine components have to be considered as a chain, so that the resulting annual crash times must be too pessimistic. Both approaches have the community, that they do not represent the daily operating of a storage ring adequately. An operator is expected to fill a storage ring (if no ramps are necessary) in a few minutes. So a crash scenario which lasts hours is unrealistic. The second point is, that storage rings are not optimized to decrease the injection time to the lowest possible level, they are optimized to fulfill the requirements of the users which are often in contradiction to a good machine performance. The third point is, that the injetion times are usually short, so also for synchrotron and microtron a more stable operating state is as least as important as a state with a higher performance but more unstable conditions.

So we start a new approach with the ansatz, that a typical injection time is longer than the optimal case. From the experiences at BESSY I we chose a lengthening factor of 3 for the user mode, and a factor of 30 for the machine test mode. The reason for the lengthening must be a failure function of one of the machine components as specified in the last section with equal probability. The failure function or crash probabilities follows results from the lengthening factors. So we differ between four modes. The user (1) and the machine test mode (3) and the user (2) and machine test mode (4) with failure functions. Te result for the annual operting times for the four modes for every machine component is then:

$$
\begin{gathered}
t_{i}^{(1)}=t_{\max } \cdot \prod_{k=1}^{i}\left(1-P_{U}\right) \\
t_{i}^{(2)}=t_{\max } \cdot P_{U} \cdot \prod_{k=1}^{i-1}\left(1-P_{U}\right) \\
t_{i}^{(3)}=t_{\max } \cdot \prod_{k=1}^{i}\left(1-P_{M}\right) \\
t_{i}^{(4)}=t_{\max } \cdot P_{M} \cdot \prod_{k=1}^{i-1}\left(1-P_{M}\right)
\end{gathered}
$$

$P_{U}$ is the failure function probability for the user mode, $P_{M}$ for the machine test mode.

The $t_{\text {max }}$ are:

$t_{\max }$ User mode

$300 \mathrm{~h} / \mathrm{a}$

$t_{\text {max }}$ User mode injection time $\quad 20 \mathrm{~h} / \mathrm{a}$

$t_{\max }$ Machine test mode $\quad 150 \mathrm{~h} / \mathrm{a}$

$t_{\max }$ Machine test mode injection time $100 \mathrm{~h} / \mathrm{a}$

\section{RESULTS}

The outer wall of the storage ring is dimensioned $1 \mathrm{~m}$ normal concrete and at the beamline angles $1 \mathrm{~m}$ heavy concrete with $5 \mathrm{~cm}$ lead stripe (beam height $\pm 20 \mathrm{~cm}$ ), at the injection $10 \mathrm{~cm}$ lead and $10 \mathrm{~cm}$ lead transversal of the injection septum. The outer wall of the synchrotron is dimensioned $1.1 \mathrm{~m}$ normal concrete.

The inner normal concret walls and the roofs of both storage ring and synchrotron are $0.7 \mathrm{~m}$ thick. The roofs are of heavy concrete above the area between extraction

\begin{tabular}{|c|c|c|c|c|}
\hline$-\dot{H}_{1}$ & $2.27 e-01$ & Sv/h & $\gamma-\dot{H}_{S}$ & $1.21 e-07$ \\
\hline$-H_{U}$ & $1.28 e-06$ & Sv/a & $\gamma-H_{M}$ & $4.31 e-07$ \\
\hline$-\dot{H}_{1}^{t o t}$ & $1.36 e+01$ & Sv/h & $\gamma-\dot{H}_{S}^{t} o t$ & $7.29 e-06$ \\
\hline$-H_{U}^{\frac{1}{t o t}}$ & $9.47 e-06$ & Sv/a & $\gamma-H_{M}^{t o t}$ & $1.16 e-05$ \\
\hline 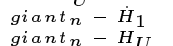 & $\begin{array}{l}6.87 e-03 \\
2.77 e-05\end{array}$ & $\begin{array}{l}\text { Sv/h } \\
\text { Sv/a }\end{array}$ & $\begin{array}{l}\text { giant }_{n}^{M}-\dot{H}_{S} \\
\text { giant }_{n}-H_{M}\end{array}$ & $\begin{array}{l}2.63 e-06 \\
9.34 e-06\end{array}$ \\
\hline giant $_{n}-\dot{H}_{1}^{\text {tot }}$ & $4.12 e-01$ & Sv/h & giant $_{n}-\dot{H}_{S}^{t_{0}}$ & $1.58 e-04$ \\
\hline giant $_{n}-H_{U}^{\text {tot }}$ & $2.05 e-04$ & Sv/a & giant $_{n}-H_{M}^{t_{0} t}$ & $2.52 e-04$ \\
\hline $\begin{array}{l}\text { fast }_{n}-\dot{H}_{1} \\
\text { fast }_{n}-H_{N}\end{array}$ & $\begin{array}{l}2.88 e-04 \\
6.86 e-05\end{array}$ & $\begin{array}{l}\text { Sv/h } \\
\text { Sv/a }\end{array}$ & $\begin{array}{l}\text { fast }_{n}=\dot{H}_{S} \\
\text { fast }_{n}=H_{M}\end{array}$ & $\begin{array}{l}6.53 e-06 \\
2.31 e-05\end{array}$ \\
\hline$a_{s t_{n}}-\dot{H}_{1}^{t o t}$ & $1.73 e-02$ & $\mathrm{~Sv} / \mathrm{h}$ & fast $_{n}-\dot{H}_{S}^{t o t}$ & $3.92 e-04$ \\
\hline fast $_{n}-H_{U}^{\text {tot }}$ & $5.09 e-04$ & Sv/a & fast $_{n}-H_{M}^{\text {tot }}$ & $6.24 e-04$ \\
\hline
\end{tabular}
septum, transferline synchrotron storage ring and injection septum.

Table 3: Storage ring, point source transversal outside

The complete calculated annual dose is $1.74 \mathrm{mSv} / \mathrm{a}$, which is similar to the measured value for 1998 of 1.2 mSv/a. (3.8 mSv/a at injection). The measured $\gamma$ doserates are close to the calculated values, the measured neutron doserates are typically a factor of two lower than the calculations.

\section{REFERENCES}

[1] K. Ott: Sicherheitsbericht für den Betrieb der Speicherringanlage BESSY II in Berlin - Adlershof, Tech. Rep. S4/97 BESSY (1997)

[2] E. Bräuer, K. Tesch: Data on muon doses behind thick shielding at electron accelerators, DESY D3-62 (1987)

[3] H. Dinter, J. Pang, K. Tesch: Calculations of doses due to electron-photon stray radiation from a high energy electron beam behind lateral shielding. Rad. Prot. Dos. 25,2 p107 (1988)

[4] A. Esposito, M. Pellicioni: Gas bremsstrahlung production in the ADONE storage ring, LNF-86/23(NT) (1986)

[5] S.-H. Jiang, J.-P. Wang: Detail conceptual shielding design of SRRC, SRRC-1-SA8 Rev819 (1988)

[6] K. Tesch: Strahlenschutz für die $800 \mathrm{MeV}$ Speicherringanlage BESSY. Tech. Rep. 2 BESSY (1978)

[7] K. Tesch: Data for simple estimates for shielding against neutrons at electron accelerators. Part. Acc. 9, p201 (1979)

[8] K. Tesch: Shielding against high energy neutrons from electron accelerators - a review. Rad. Prot. Dos. 22,1 p27 (1988) 